\title{
The role of condensing and non-condensing solvents in SA-SAGD
}

\author{
Mira Kim
}

\begin{abstract}
Recent development of high-temperature high-pressure glass micromodels has allowed physical modeling of the SAGD and solvent-SAGD processes at conditions similar to the Canadian Oil Sands. This presents an opportunity to study the performance of various solvents on bitumen production under relevant in-situ reservoir condition. The results of this paper showed that C6-SAGD run showed the highest enhancement in oil recovery due to its thermophysical properties being similar to steam; C4-SAGD run showed a high improvement in the oil recovery rate due to the foam layer reducing the viscous fingering phenomena, and the condensation of these bubbles aiding the fast flow of this zone; C3-SAGD run showed a foam layer in the mobile zone which reduced the viscous fingering phenomena; and a fluorescence analysis of C6-SAGD run showed a varying level in fluorescence intensity due to separation of aromatic components of bitumen.
\end{abstract}

\section{Index Terms-Bitumen, SAP, SA-SAGD, Micromodel}

\section{INTRODUCTION}

Petroleum contributes to $33 \%$ of the world's energy supply with one of the major uses being in transportation $[1,2]$. Though oil is inherently a limited resource, the newly-developed production technologies have increased its supply by increasing the amount of economically recoverable oil, so-called as oil reserves. The introduction of steam-assisted gravity drainage (SAGD) by Butler in 1970s, where the main mechanism relies on the viscosity reduction of bitumen due to large amount of heat transfer, has significantly enlarged the Canadian oil reserves [3-6]. In the SAGD process, a horizontal well is drilled one above the other in the same vertical plane, and large volume of steam is continuously injected from the upper horizontal well, developing a steam chamber and transferring large amount of heat to bitumen via latent heat generation because of steam condensation. Consequently, the viscosity of bitumen drastically declines, making the bitumen mobile enough to be drained by gravity towards the lower horizontal well and produced together with condensed steam, as depicted in Fig. 1.

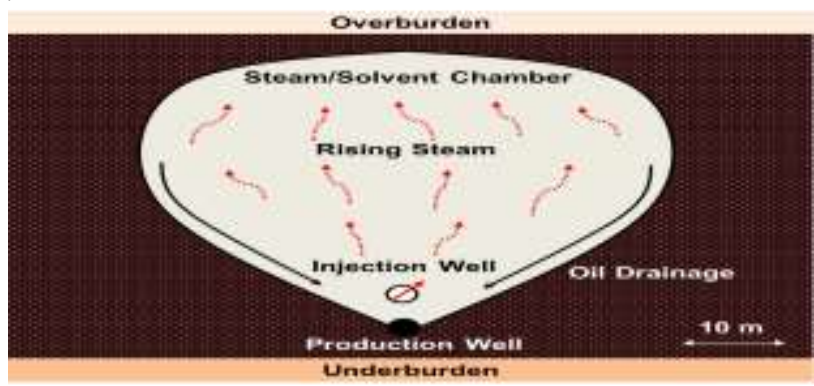

Fig. 1 Concept diagram of SAGD and solvent-SAGD process.

Mira Kim, Mechanical and Industrial Engineering, University of Toronto, Toronto, Canada
While SAGD is effective, it has economic and environmental issues associated with steam generation. Several methods have been developed to address the issues as well as to improve the bitumen extraction over SAGD. In this regard, the use of light solvents to reduce the viscosity of bitumen through dilution, known as vapor extraction (VAPEX), has been proposed [7-10]. Furthermore, a hybrid method of co-injecting a minor volume of solvents (5-15 vol\%) with steam has been implemented showing promising results in increasing bitumen recovery and reducing energy costs [11-18]. This process is known as solvent-aided steam assisted gravity drainage (SA-SAGD), or expanding solvent steam assisted gravity drainage (ES-SAGD), its name derived from the expansion characteristic of solvents over the steam. The benefits of solvent injection in steam is not only limited to the increase in oil recovery due to viscosity reduction of bitumen, but also in that the produced solvent can be recycled and re-injected into the reservoir, and that the produced solvent in the oil phase offsets solvents required to make the bitumen pipelinable which indicates a good opportunity for field application [3].

During the steam injection process in the bitumen reservoir, the porous structure of the reservoir rock significantly influences the recovery rate [19-24]. The existence of three-phase flow (i.e., steam, water and bitumen) additionally complicates the displacement process. A detailed understanding of the porous media properties such as porosity and permeability together with pore scale physical phenomena can bring methods of enhancement to the oil recovery process and be incorporated in mathematical models numerically simulating the oil recovery process. Macroscopic multi-phase flow is difficult to model experimentally, and two-phase or three-phase relative permeability and capillary pressure data are usually estimated by appropriately averaging the equations describing the physical processes occurring in the pore scale [19]. However, this approach requires a thorough understanding of displacement mechanisms on the pore scale and a complete description of the pore space morphology. Direct visual observation of the multiphase flow during the SAGD process provides an opportunity to probe recovery mechanisms and pore-scale phenomena that take place in the reservoir.

Though the application of microfluidics for research has mostly been in the biomedical sector, the glass microfluidic chip provides an opportunity for visualization of oil recovery processes due to its capacity to work in high-pressure and high-temperature conditions, and it is compatibly to harsh solvents [25-27]. Microfluidics applications for energy have led to interesting research such as detection of minimum miscibility pressure (MMP) of $\mathrm{CO}_{2}$ in heavy oil [28], and measurement of $\mathrm{CO}_{2}$ diffusion in water and brine for carbon sequestration [29]. The application of microfluidics in research brings advantages as many orders of reduction in 
sample size, rapid quantification, facile control of temperature and pressure, and operating cost reduction [30]. In this paper, SAGD micromodel runs were conducted with various solvents at high temperatures and pressures (e.g. 1.0 $\mathrm{MPa}$ ) relevant to in situ reservoir conditions. Visualization techniques were used to analyze the oil recovery factor and pore scale mechanisms, and the effects of different solvents injected with steam were investigated in macroscopic, pore scale and microscopic scales, coinciding with previous conclusions in literature [14-16], and adding new insights in the solvent-SAGD process through pore scale and microscopic studies.

\section{EXPERIMENTAL METHODS}

A glass chip was fabricated to resemble the pore geometry of a typical bitumen oil sand formation and a PEEK manifold was used for better insulation during the run. Fig. 2 shows the overall schematic for the solvent-SAGD tests. DI Water and solvents were first fed into high-pressure syringe pumps (Teledyne Isco 260D) then were co-injected to the steam generator at controlled flowrates. The pressure was manually controlled through the backpressure regulator (Equilibar, EBIZF1) and through the pumps. The flowrates of the runs were set based on the required convection to reach the desired test temperatures. During the run, a Nikon D3300 camera was used to study the oil recovery of the micromodel and a digital microscope (Dinolite AD-4013TL) was used to study pore scale phenomena in the solvent-SAGD process. An IR camera (RAR-IR Nano camera) was used to read the temperature profile of the chip. After the run was terminated, post run analysis was conducted by a fluorescence microscope (Olympus BXFM 5x objectives). Fig. 2 is a schematic of the experimental setup.

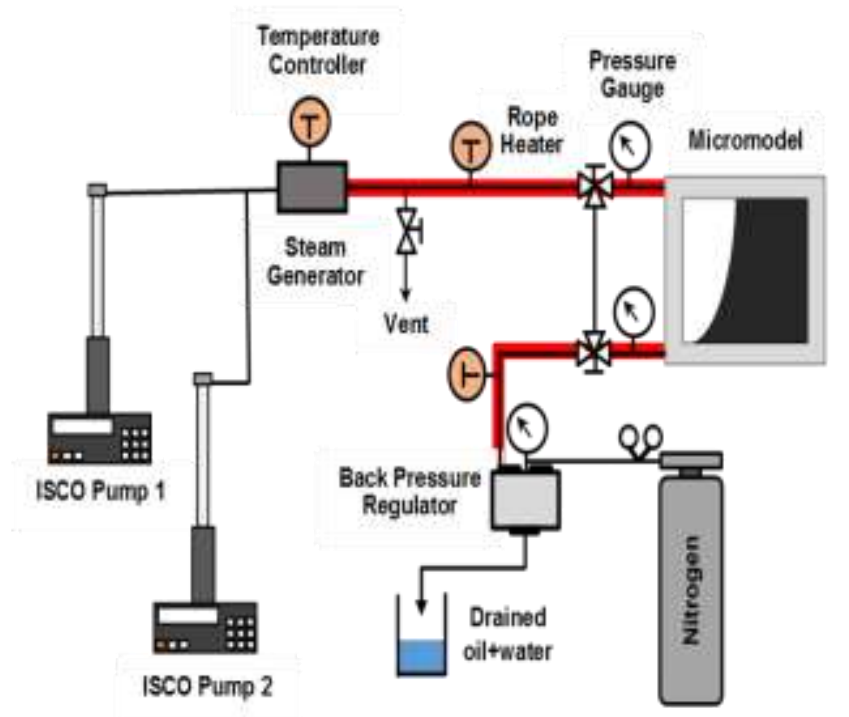

Fig. 2 Schematic diagram of solvent-SAGD setup.

Table 1 is a summary of the experimental conditions of the solvent-SAGD runs. The runs were performed at 1.0 MPa, and the flowrate was set to $1 \mathrm{ml} / \mathrm{min}$ for water, and $0.1 \mathrm{ml} / \mathrm{min}$ for solvents. The condensate solvent was not a single component solvent but a mixture of light and heavy hydrocarbons.
Table 1 Operating conditions of SAGD and solvent-SAGD micromodel runs.

\begin{tabular}{|c|c|c|c|}
\hline Run & $\begin{array}{c}\text { Pressure } \\
(\mathrm{MPa})\end{array}$ & Flowrate $(\mathrm{ml} / \mathrm{min})$ & $\begin{array}{l}\text { Temp } \\
\left(\begin{array}{ll}(0 & C\end{array}\right)\end{array}$ \\
\hline SAGD & 1.0 & $1 \mathrm{ml} / \mathrm{min}$ (DI water) & 185 \\
\hline $\begin{array}{l}\text { Condensate- } \\
\text { SAGD }\end{array}$ & 1.0 & $\begin{array}{c}1 \mathrm{ml} / \mathrm{min} \text { (DI water) }+ \\
0.1 \mathrm{ml} / \mathrm{min} \text { (solvent) }\end{array}$ & 185 \\
\hline C6-SAGD & 1.0 & $\begin{array}{c}1 \mathrm{ml} / \mathrm{min} \text { (DI water) }+ \\
0.1 \mathrm{ml} / \mathrm{min} \text { (solvent) }\end{array}$ & 185 \\
\hline C4-SAGD & 1.0 & $\begin{array}{c}1 \mathrm{ml} / \mathrm{min}(\mathrm{DI} \text { water})+ \\
0.1 \mathrm{ml} / \mathrm{min} \text { (solvent) }\end{array}$ & 185 \\
\hline C3-SAGD & 1.0 & $\begin{array}{c}1 \mathrm{ml} / \mathrm{min} \text { (DI water) }+ \\
0.1 \mathrm{ml} / \mathrm{min} \text { (solvent) }\end{array}$ & 185 \\
\hline
\end{tabular}

\section{RESULTS AND DISCUSSION}

\section{A. Macroscopic analysis}

Fig. 3 shows the overall chip images of the SAGD and solvent-SAGD runs at three different time frames: 15 minutes, 30 minutes, and 85 minutes. At a timeframe of 15 minutes, a rapid steam chamber development had taken place, and the oil recovery process has begun to represent the borderline phenomena of the steam chamber in the oil field reservoir during the SAGD process. The SAGD, condensate-SAGD, and C6-SAGD run did not differ significantly. For the C4-SAGD run, the clearing at 15 minutes of the run is quite smaller, compared to the SAGD run. This is primarily due to the gas blanket effect, the solvent gas chamber dispersing faster and acting as a thermal insulation layer, impeding the heat transfer of steam [16].

At 30 minutes of the run, major differences in the color of the mobile zone between the SAGD and the solvent-SAGD runs can be observed. The color of the mobile zone of the SAGD run are in black and white, white being the water region, and black being the bitumen region. However, the mobile zones of the solvent-SAGD runs have a lighter color because of dissolution effect of solvents in bitumen. Also, the difference between condensate-SAGD run and C6-SAGD run can be observed from this timeframe. The condensate-SAGD run has a fuzzy boundary at the top region of the micromodel which is thought to be due to the lighter hydrocarbons that are in the gas phase. The C6-SAGD run on the other hand, shows an even distribution of the mobile zone, which continues until the end of the run. The C4-SAGD run shows a fuzzy boundary in the interface, and shows a good development of the steam and solvent chamber from the first 15 minutes.

At 85 minutes into the run, there are major differences between all the runs. The SAGD run shows the cleared zone, the black and white mobile zone, and the untouched bitumen zone. Both the condensate-SAGD run and C6-SAGD run show the mobile zone to be thicker than that of the SAGD run. For the condensate-SAGD, the thickness of this mobile zone varying in height can be observed. The mixture of light and heavy hydrocarbons with varying boiling points in the condensate-SAGD run seemed to have various solvents expand at different rates causing an uneven growth of this thick condensation zone. It is speculated that lighter hydrocarbons expanded to the top region and the heavier hydrocarbons dissolved the bottom region of the mobile zone. For the hexane-SAGD run, a uniformity in this mobile region from the top to the bottom is observed, similar to that from 30 minutes of the run. The expansion of steam and solvent 
chamber for the C6-SAGD run was noticeably effective as the vaporization temperature of hexane is close to that of water [14]. The C4-SAGD run showed a continuous improvement and a quite steady clearing of oil, indicating a positive effect of the dissolution effect after the initial stages of the run.

Fig. 3b shows the steam chamber advancement of the SAGD and solvent-SAGD runs. In the temperature scale between $20^{\circ} \mathrm{C}$ and $160^{\circ} \mathrm{C}$, a distinct red zone exists corresponding to the steam chamber of the macroscopic images. As heat transfer is the main mechanism of steam condensation, the significantly higher temperature shown as the red zone corresponds to the steam zone of the micromodel, and its boundary closely matches the condensation line of steam. For the solvent runs, the solvents expanding over this region can be identified as solvents recover oil through mass transport effects as well as heat transfer effects.

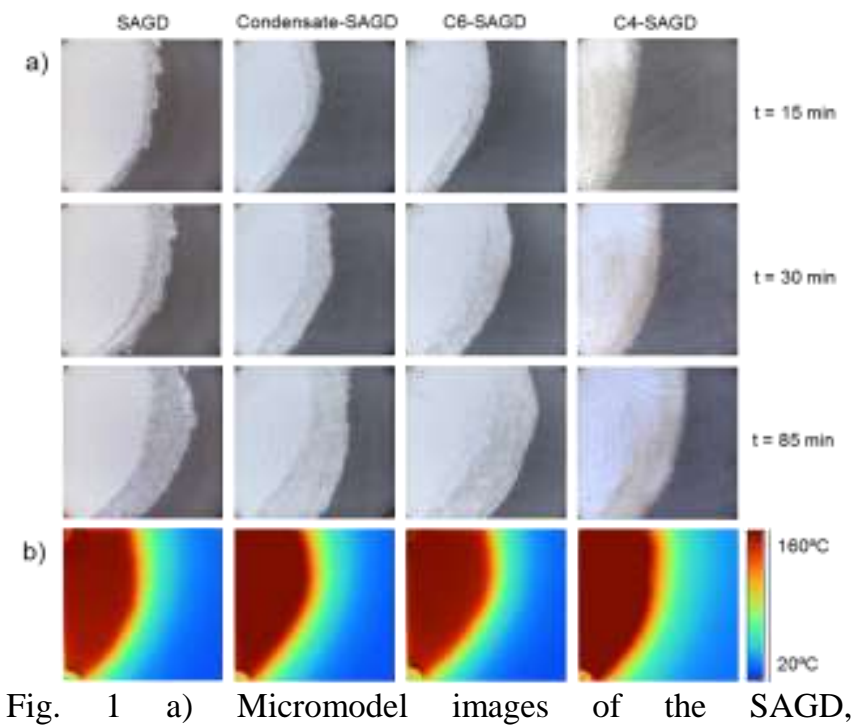

Fig. 1 a) Micromodel images of the SAGD, condensate-SAGD, C6-SAGD and C4-SAGD run at different time frames, b) IR images of SAGD, condensate-SAGD, C6-SAGD, and C4-SAGD run at 85 minutes.

Fig. 4 shows the oil recovery factor of all the runs. It is noteworthy to mention that the recovery factor point has been adjusted to start from the 5 minutes of the start of the run, due to its rapid channel clearing, and its sensitivity to pressure, temperature and flowrate which was manually adjusted in the first 5 minutes of the run. The condensate-SAGD run, and the C6-SAGD run both showed a continuous improvement in oil recovery factor, especially at the later stages of the run, when oil recovery due to steam condensation was drastically reduced as a thick water and viscous fingering layer has been developed impeding further heat transfer to bitumen in the SAGD run. In the case of the condensate-SAGD and the C6-SAGD, the solvents had an effect of reducing bitumen viscosity through mass transfer effects, which allowed oil to be continuously recovered even after the formation of a water layer. For the lighter hydrocarbons, as C3 and C4, the oil recovery in the initial stages of the run was low, due to the difference in the vaporization temperature of water and solvents. The light hydrocarbon gas formed a gas blanket, impeding the heat transfer of steam. However, after the initial stage of the run, the lighter hydrocarbons showed an enhancement in the oil recovery compared to the SAGD run, which showed the effect of solvents aiding the bitumen recovery.

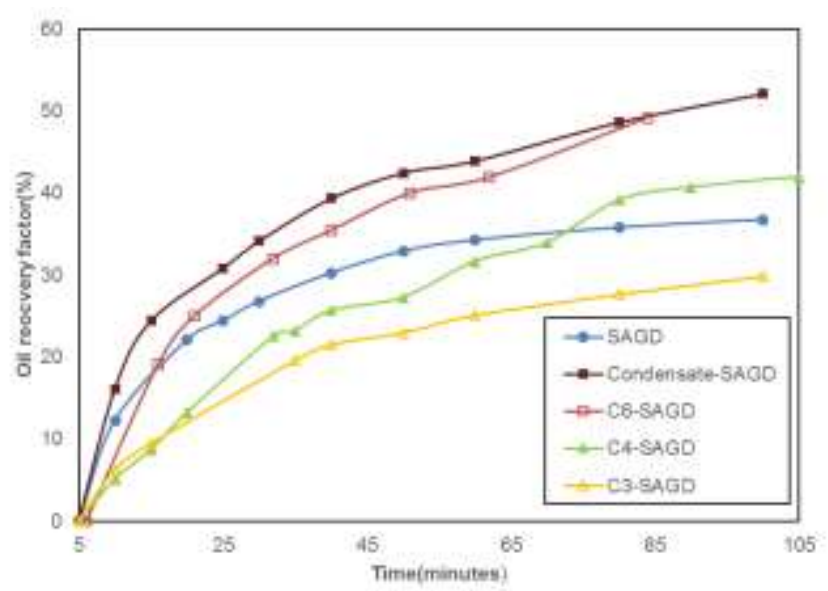

Fig. 4 Oil recovery factor of the SAGD and solvent-SAGD runs.

Fig. 5 shows the average oil recovery rate for the SAGD and solvent-SAGD runs after the 40 minutes of the run, when fast clearing due to steam condensation effect has slowed down. First, it can be noticed that all the solvent-SAGD runs have an improved oil recovery rate compared to the SAGD run showing the effect of viscosity reduction through solvent dilution in bitumen. The effectiveness of C6-SAGD can be described through the similarity in the thermophysical properties of hexane to water in the conducted experimental conditions (1.0 $\mathrm{MPa})$ relevant to reservoir conditions. Another observation that can be observed is the unexpected effectiveness of the C4-SAGD run. Though the initial gas blanket effect was observed in the C4-SAGD run, a high oil recovery rate was observed in the C4-SAGD run after this initial stage, and a mechanistic study of this phenomena was conducted during the pore scale analysis of C4-SAGD.

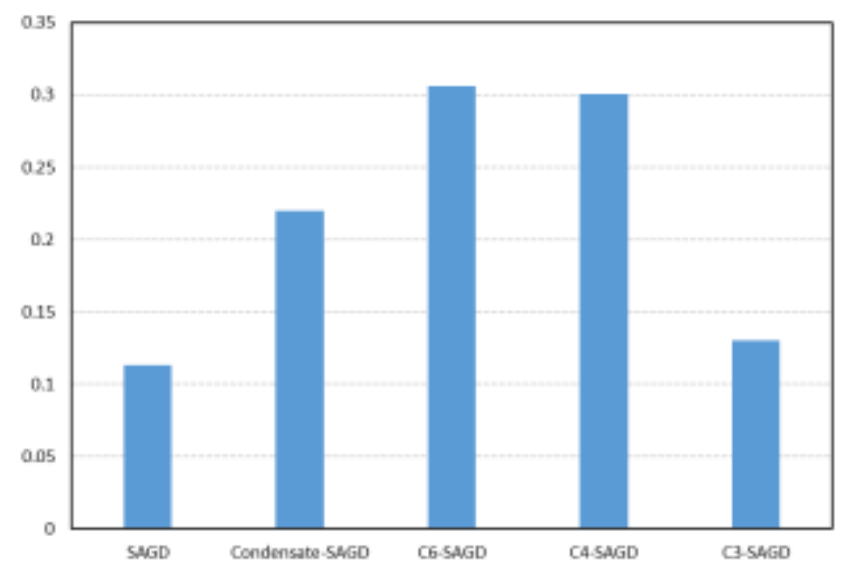

Fig. 5 Average oil recovery rate $(\% / \mathrm{min})$ of solvent-SAGD runs after 40 mins.

\section{B. Pore scale analysis}

Fig. 6 shows the magnified view of the C6-SAGD run. A magnified view of this zone shows primarily, a change of color gradient throughout this region. This happens as steam and hexane is continuously injected, the inner part of the mobile zone has been washed away by hexane and water, while the mobile zone layer close to the bitumen zone is being diluted by hexane. Hence, the mobile zone shows an increase in the darkness of color as it gets closer to the bitumen zone. Another interesting observation with this zone is the existent 
of small black particles in the mobile zone near to the steam chamber. These black particles are asphaltenes, component of bitumen that does not get diluted in n-alkanes [31].
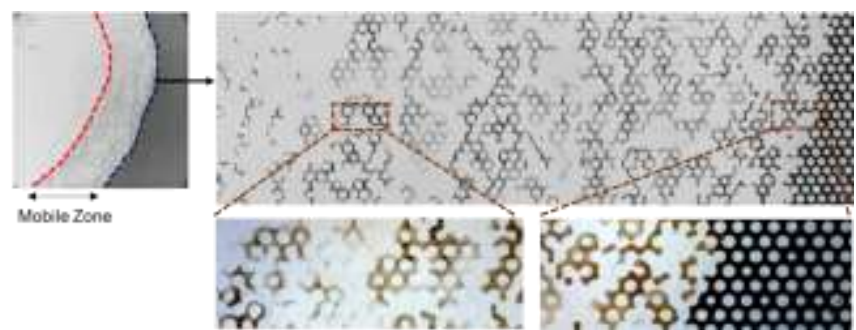

Fig. 6 Pore scale images into the hexane-SAGD run of the mobile zone.

Fig. 7 shows the snapshot of the pore scale images during the pure SAGD run, C6-SAGD run and condensate-SAGD run. Fig. 7a shows the pore scale image of the interface region of the pure SAGD run, where the only black and white region can be observed, and round viscous fingering layer is observed due to the immiscibility of water and bitumen. Fig. $7 \mathrm{~b}$ is a pore scale image of the interface region in the C6-SAGD run and Fig. 7c is a pore scale image of the interface region in the condensate-SAGD run. While a very clear dilution and clearing of the oil zone was observed in C6-SAGD run, some messier boundaries were observed in the condensate-SAGD run. A fast oil drainage in the mobile zone near the bitumen zone was found in the C6-SAGD run, as hexane expanded over the condensed steam and reduced the bitumen viscosity through mass transport effects as well as heat transfer effects during its condensation. In the condensate-SAGD run, due to the different phases of solvents in the condensate solvent mixture, the mobile zone differed from height. Fig. 7c depicts the bottom layer of the mobile zone where some wettability alteration is found. The difference between Fig. $7 \mathrm{~b}$ and Fig. $7 \mathrm{c}$ is that while hexane expanded over the steam condensation line condensing after steam for the C6-SAGD run, the heavier liquid solvent in the condensate-SAGD run met with bitumen and diluted the bitumen but did not fully clear it.
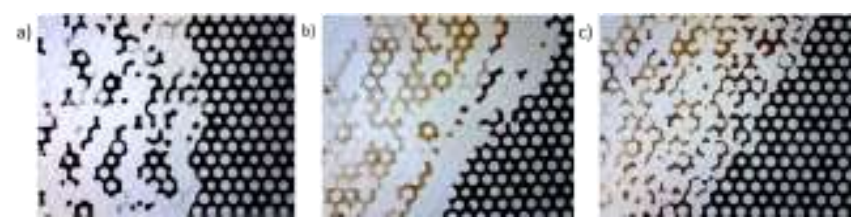

Fig. 7 Pore scale comparison images of SAGD, C6-SAGD, and condensate-SAGD run.

Fig. 8a is a magnification of the mobile zone and time lapsed pore scale images taken during the C4-SAGD run. In the C4-SAGD run, the viscous fingering layer of the mobile zone had been cleared, and was mostly occupied by bubbles. However, unlike the C3-SAGD run, the sweeping efficiency of this butane bubbles were high. A closer look in the IR images showed that butane bubbles condensed in the mobile zone, and the condensation of butane bubbles would have brought high flow in this region. The high effectiveness of the C4-SAGD run is thought to be due to the combined effect of bubbles reducing the mobility of the penetrating fluid and reducing the viscous fingering phenomena [32], bubble condensation leading to fast flow in the mobile zone, and the dissolution of butane in bitumen. The pore scale analysis of the C4-SAGD showed a 3.19\% recovery improvement over 5 seconds in the captured pore scale region as shown in Fig. 8a.

Fig. $8 \mathrm{~b}$ is the magnification of the interface region and a time lapsed pore scale images taken during the C3-SAGD run. Propane bubbles were observed in the interface region. The flow of the propane bubbles was slow and sluggish, and these bubbles sweeping the mobile zone was observed. The mobile zone region was better cleared than the other runs, as the foam bubbles increased the viscosity of the propane water fluid, lowering its mobility and reducing the viscous fingering phenomena. In Fig. 8b, the bubbles were clearly captured in the mobile zone layer in the Nikon images as the flow as slower, as well as in the pore scale images. The pore scale analysis in the C3-SAGD run showed a $0.58 \%$ improvement in recovery over 5 seconds significantly lower than that of the C4-SAGD run.

\section{a) C4-SAGD (fast flow in mobile zone)}

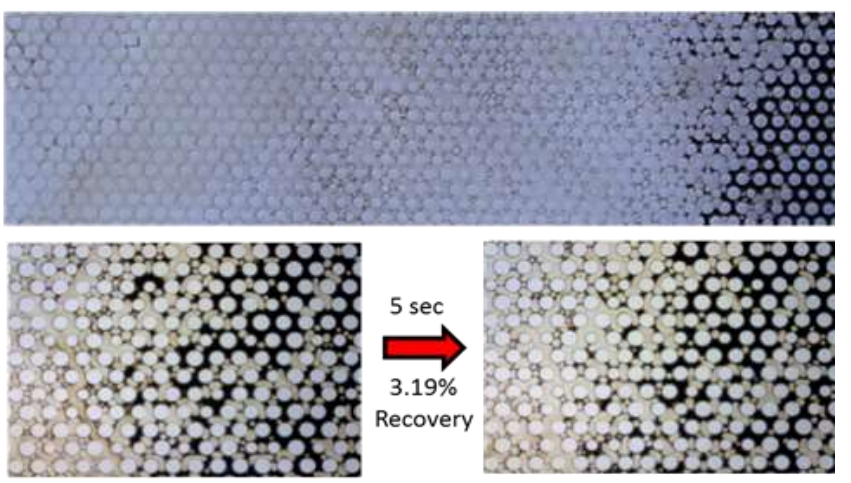

b) C3-SAGD (slow flow in mobile zone)

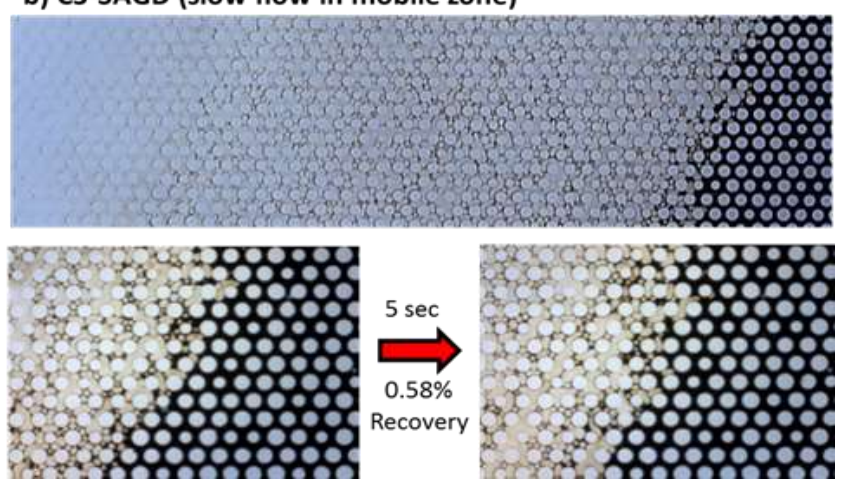

Fig. 8 a) Mobile zone of the C4-SAGD run at 85 minutes, time lapsed pore scale images, and improved recovery in the pore scale analysis, and b) mobile zone of the C3-SAGD run at 85 minutes, time lapsed pore scale images, and improved recovery in the pore scale analysis.

\section{Fluorescence microscopy analysis}

After terminating the runs, microscopic images of the micromodel were taken to further analyze the phenomena that happens during the run. Fig. 9 shows microscopic images in the interface region of the C6-SAGD run. Fig. 9a is a darkfield microscopic image of the interface region near the bitumen zone of the C6-SAGD run and Fig. 9b is the corresponding fluorescence microscopic image of it. In Fig. 9a there are two distinct regions in the bitumen hexane interface, and region $\mathrm{A}$ is visually darker in color than region B. Looking at these two regions under the fluorescence microscope as in Fig. 9b, region B is significantly brighter in fluorescence intensity. This phenomenon can be explained through studies in bitumen microstructure, and saturate-aromatics-resin-asphaltene (SARA) analysis of 
bitumen. The SARA components of bitumen have been investigated in their visual observation and their fluorescence signal, showing the aromatics to have a higher fluorescence intensity compared to the other components, and asphaltenes to have basically no fluorescence [31]. The components itself vary in color, from saturates being a clear colorless liquid, aromatics being lighter brown, resins being darker brown, and asphaltenes being black [33,34]. Hence, the reason why region B in Fig. 9 has a higher fluorescence intensity can be explained by the higher composition of aromatics in region $\mathrm{B}$, due to its lower polarity and higher solubility in hexane. A quantification along the transition zone is shown in Fig. 9c.

Fig. 9d-f shows darkfield and corresponding fluorescence microscopic images of the C6-SAGD run near the steam boundary of the interface region. Fig. 9d shows the darkfield microscopic image of this region and Fig. 9e shows the corresponding fluorescence microscopic image of it. Black particles that basically showing no fluorescence can be observed in the clear colorless liquid region that shows minor fluorescence. These black particles labeled as Region D are asphaltenes, and the lighter brown region labeled Region $\mathrm{C}$ has a significantly higher fluorescence intensity due to a higher fraction of aromatics. Fig. 9f shows the fluorescence intensity in line $\mathrm{fg}$, and quantifies the higher fluorescence intensity in region $\mathrm{C}$. a)

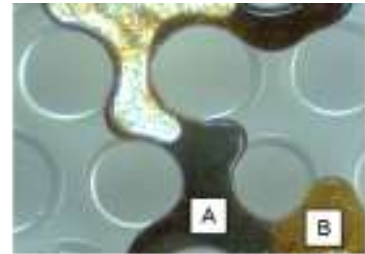

b)

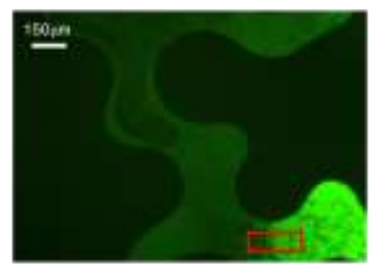

c)

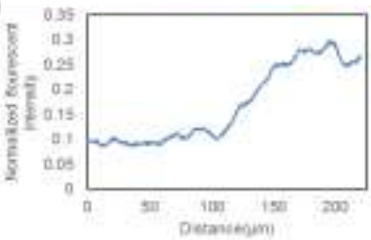

d)

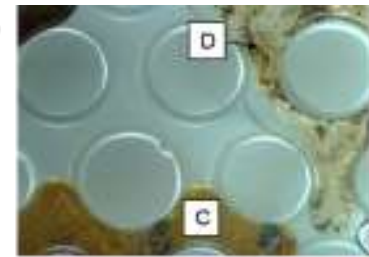

e) 3

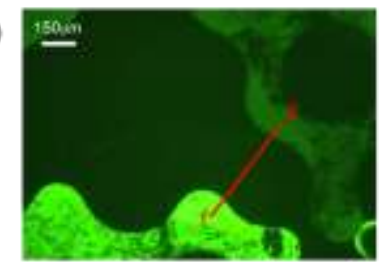

f)

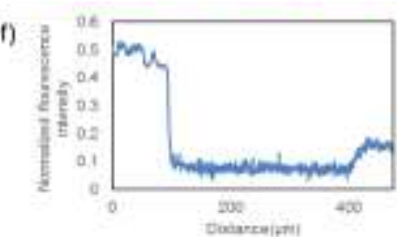

Fig. 9 a) Darkfield microscopic image of interface region near the bitumen zone for C6-SAGD run, b) corresponding fluorescence microscopic image of a), c) quantification of the fluorescence signal along the red marked region, d) darkfield microscopic image of interface region near the steam zone for C6-SAGD run, e) corresponding fluorescence microscopic image of d), and f) quantification of the fluorescence signal along the red line fg.

The post run analysis of C3-SAGD run is shown in Fig. 10. Here, the formation of bitumen residue can be observed along the propane bubbles that was formed during the run. Fig. $10 \mathrm{a} \& \mathrm{~b}$ shows the bitumen residue formed along the trapped propane bubbles in the interface region near the bitumen zone under the darkfield and fluorescence microscopy. Fig. 10c\&d shows the bitumen residue that condensed in a foamy structure close to the steam chamber region of the interface region. a)
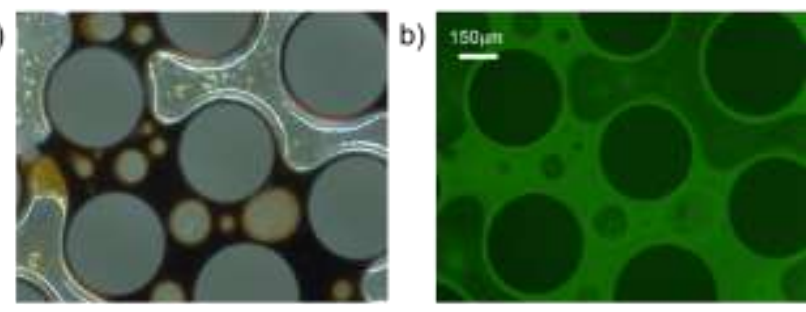

c)
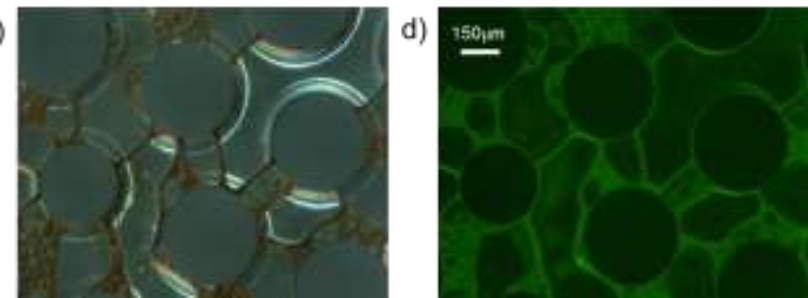

Fig. 10 a) Darkfield microscopic image of the C3-SAGD run near the bitumen region, b) corresponding fluorescence microscopic image of a), c) darkfield microscopic image of the C3-SAGD run near the steam chamber region, and d) corresponding fluorescence microscopic image of $\mathrm{c}$ ).

\section{CONCLUSION}

The micromodel analysis of solvent-SAGD brought various insights to the solvent-SAGD process, some coinciding with previous findings, and also bringing new and useful insights through pore scale and microscopic observations of the solvent-SAGD process. First, solvent co-injection to steam showed an improvement in the oil recovery due to the mass transfer effect of solvents in bitumen. The phase similarity of solvents to water effected the improvement of recovery from solvent addition to steam, and the C6-SAGD run was most effective as its thermophysical properties were closest to that of water. Lighter hydrocarbon runs eventually showed an increase of oil recovery rate compared to the pure SAGD run after the initial stages of the runs where the gas blanket effect was observed. C4-SAGD run showed a thick layer of fast dispersion of bubbles throughout the run which was effective in clearing the bitumen layer. The effectiveness of C4-SAGD is thought to be due to the clearing of the viscous fingering layer and condensation of bubbles aiding the fast flow in this region. Additionally, the microscopic analysis brought valuable insight into the compositional separation of bitumen that took place in the C6-SAGD run, due to the difference in polarity of the bitumen components and its solubility in n-alkanes.

\section{ACKNOWLEDGMENT}

Mira Kim thanks David Sinton for supervising her for this project. Suncor Energy Inc. is gratefully acknowledged for their financial support and for providing the bitumen sample to make the experiments possible. Natural Sciences and Engineering Research Council of Canada (NSERC) is also acknowledged for their funding support.

\section{REFERENCES}

[1] BP Global. BP Statistical Review of World Energy. 64th edition, 2015.

[2] Lawrence Livemore National Laboratory. Estimated U. S. Energy Use in 2013: 97. 4 Quads. (2014, March). Retrieved from https://flowcharts.llnl.gov/content/energy/energy_archive/energy_flo w_2013/2013USEnergy.png 
[3] Thomas, S. (2008). Enhanced Oil Recovery - An overview. Oil \& Gas Science and Technology, 63(1), 9-19

[4] Butler, R. M. (1994). Steam-assisted gravity drainage: concept, development, performance and future. Journal of Canadian Petroleum Technology, 33(02), 44-50.

[5] Butler, R. M., McNab, G. S., \& Lo, H. Y. (1981). Theoretical studies on the gravity drainage of heavy oil during in- situ steam heating. The Canadian journal of chemical engineering, 59(4), 455-460.

[6] Butler, R. M. (2004). The behaviour of non-condensible gas in SAGD-A rationalization. Journal of Canadian Petroleum Technology, 43(01).

[7] Fang, F., \& Babadagli, T. (2016). Three dimensional visualization of solvent chamber growth during the VAPEX processes: An experimental approach using laser. Journal of Petroleum Science and Engineering, 142, 46-67.

[8] Rezaei, N., Mohammadzadeh, O., \& Chatzis, I. (2010). Warm VAPEX: a thermally improved vapor extraction process for recovery of heavy oil and bitumen. Energy \& Fuels, 24(11), 5934-5946.

[9] Rezaei, N., Mohammadzadeh, O., \& Chatzis, I. (2010). Warm VAPEX: a thermally improved vapor extraction process for recovery of heavy oil and bitumen. Energy \& Fuels, 24(11), 5934-5946.

[10] James, L. A., Rezaei, N., \& Chatzis, I. (2007, January). VAPEX, Warm VAPEX, and Hybrid VAPEX-The State of Enhanced Oil Recovery for In Situ Heavy Oils in Canada. In Canadian International Petroleum Conference. Petroleum Society of Canada.

[11] Mohammadzadeh, O., \& Chatzis, I. (2010). Pore-level investigation of heavy oil recovery using steam assisted gravity drainage (SAGD). Oil \& Gas Science and Technology, 65(6), 839-857.

[12] Mohammadzadeh, O., Rezaei, N., \& Chatzis, I. (2010). Pore-level investigation of heavy oil and Bitumen recovery using solvent- aided steam assisted gravity drainage (SA-SAGD) process. Energy \& Fuels, 24(12), 6327-6345.

[13] Mukhametshina, A. \& Hascakir, B. Bitumen Extraction by Expanding Solvent-Steam Assisted Gravity Drainage (ES-SAGD) with Asphaltene Solvents and Non-Solvents. SPE Heavy Oil Conf. (2014).

[14] Nasr, T. N., Beaulieu, G., Golbeck, H., \& Heck, G. (2002, January). Novel expanding solvent-SAGD process "ES-SAGD". In Canadian International Petroleum Conference. Petroleum Society of Canada.

[15] Gupta, S. C., \& Gittins, S. D. (2006). Christina Lake solvent aided process pilot. Journal of Canadian Petroleum Technology, 45(09).

[16] Li, W., Mamora, D., \& Li, Y. (2011). Light-and heavy-solvent impacts on solvent-aided-SAGD process: a low-pressure experimental study. Journal of Canadian Petroleum Technology, 50(04), 19-30.

[17] Gates, I. D. (2010). Solvent-aided steam-assisted gravity drainage in thin oil sand reservoirs. Journal of Petroleum Science and Engineering, 74(3-4), 138-146.

[18] Dong, L. (2012). Effect of vapour-liquid phase behaviour of steam-light hydrocarbon systems on steam assisted gravity drainage process for bitumen recovery. Fuel, 95, 159-168.

[19] Whitaker, S. (1986). Flow in porous media I: A theoretical derivation of Darcy's law. Transport in porous media, 1(1), 3-25.

[20] Øren, P. E., \& Pinczewski, W. V. (1995). Fluid distribution and pore-scale displacement mechanisms in drainage dominated three-phase flow. In Multiphase Flow in Porous Media (pp. 105-133). Springer, Dordrecht.

[21] Olbricht, W. L. (1996). Pore-scale prototypes of multiphase flow in porous media. Annual review of fluid mechanics, 28(1), 187-213.

[22] Blunt, M. J. (2001). Flow in porous media-pore-network models and multiphase flow. Current opinion in colloid \& interface science, 6(3), 197-207.

[23] Al-Raoush, R., Thompson, K., \& Willson, C. S. (2003). Comparison of network generation techniques for unconsolidated porous media. Soil Science Society of America Journal, 67(6), 1687-1700.

[24] Feng, Q. X., Di, L. C., Tang, G. Q., Chen, Z. Y., Wang, X. L., \& Zou, J. X. (2004, January). A visual micro-model study: The mechanism of water alternative gas displacement in porous media. In SPE/DOE Symposium on Improved Oil Recovery. Society of Petroleum Engineers.

[25] Cheng, X., Ooms, M. D., \& Sinton, D. (2016). Biomass-to-biocrude on a chip via hydrothermal liquefaction of algae. Lab on a Chip, 16(2), 256-260.

[26] de Haas, T. W., Fadaei, H., Guerrero, U., \& Sinton, D. (2013) Steam-on-a-chip for oil recovery: the role of alkaline additives in steam assisted gravity drainage. Lab on a Chip, 13(19), 3832-3839.

[27] Kim, M., Abedini, A., Lele, P., Guerrero, A., \& Sinton, D. (2017). Microfluidic pore-scale comparison of alcohol-and alkaline-based SAGD processes. Journal of Petroleum Science and Engineering, $154,139-149$.
[28] Nguyen, P., Mohaddes, D., Riordon, J., Fadaei, H., Lele, P., \& Sinton, D. (2015). Fast fluorescence-based microfluidic method for measuring minimum miscibility pressure of $\mathrm{CO}_{2}$ in crude oils. Analytical chemistry, 87(6), 3160-3164.

[29] Sell, A., Fadaei, H., Kim, M., \& Sinton, D. (2012). Measurement of $\mathrm{CO}_{2}$ diffusivity for carbon sequestration: A microfluidic approach for reservoir-specific analysis. Environmental science \& technology, 47(1), 71-78.

[30] Song, W., Fadaei, H., \& Sinton, D. (2014). Determination of dew point conditions for $\mathrm{CO}_{2}$ with impurities using microfluidics. Environmental science \& technology, 48(6), 3567-3574.

[31] Handle, F., Füssl, J., Neudl, S., Grossegger, D., Eberhardsteiner, L., Hofko, B., ... \& Grothe, H. (2016). The bitumen microstructure: a fluorescent approach. Materials and Structures, 49(1-2), 167-180.

[32] Nguyen, P., Fadaei, H., \& Sinton, D. (2014). Pore-scale assessment of nanoparticle-stabilized $\mathrm{CO} 2$ foam for enhanced oil recovery. Energy \& Fuels, 28(10), 6221-6227.

[33] He, L., Li, X., Wu, G., Lin, F., \& Sui, H. (2013). Distribution of saturates, aromatics, resins, and asphaltenes fractions in the bituminous layer of athabasca oil sands. Energy \& Fuels, 27(8), 4677-4683

[34] Marufuzzaman, M. (2010). Solubility and diffusivity of carbon dioxide, ethane and propane in heavy oil and its SARA fractions (Doctoral dissertation, University of Regina).

Mira Kim is currently a researcher at McGill University. Mira Kim specialized in oil research and fluid mechanics. Mira Kim has obtained a Master of applied science degree from University of Toronto. 